\title{
Scripta
}

\section{«Todo tosco y sin labrar»: el model conventual de santa Teresa i el seu reflex en la normativa arquitectònica de l'orde carmelità descalç}

\section{«Todo tosco y sin labrar»: The model of monastery in Saint Teresa's mind and its reflection in the architectural rules of the Discalced Carmelites religious order}

Carme Narváez narvaez@ub.edu

Universitat de Barcelona

Resum: El concepte de vida de clausura plantejat per santa Teresa va determinar la naturalesa de les edificacions escomeses en el si de la congregació de carmelites descalços. La senzillesa i l'estretor requerits per la fundadora en l'establiment dels nous convents esdevingueren preceptes d'obligat compliment per part de les autoritats de l'orde, i quedaren recollits en les diverses constitucions internes generades al llarg dels segles XVI, XVII i XVIII. Aquest article analitza els models constructius establerts des dels inicis de l'existència de la congregació i la manera en què van ser aplicats amb posterioritat.

Paraules clau: santa Teresa, carmelites descalços, normativa, convent, traça

Abstract: The concept of life in enclosed monastery set out by Saint Teresa determined the nature of the buildings tackled in the breast of the congregation of Discalced Carmelites. The simplicity and the narrowness required by the founder in the establishment of the new convents, turned into precepts of forced fulfillment by part of the authorities of the religious order, and they remained collected in the diverse internal constitutions generated along the 17 th and 18th centuries. This article analyses the constructive models established since the beginning of the congregation and the way in which they were applied subsequently.

Keywords: Saint Teresa, Discalced Carmelites, precepts, monastery, architectural design

\footnotetext{
* Aquest treball s'emmarca en el projecte d'investigació ACAF/ART III, «Análisis crítico y fuentes de las cartografías del entorno visual y monumental del área mediterránea en época moderna» (HAR2012-32680), finançat pel Ministerio de Economía y Competitividad.
} 
L'establiment de congregacions religioses de nova creació en l'àmbit hispànic dels segles XVI i XVII va ser determinant per a l'expansió dels esquemes constructius etiquetats com a contrareformistes. Van ser instituts religiosos com els dels caputxins, jesuïtes o carmelites descalços els que, a partir de les fundacions de llurs convents, van afavorir més decididament la difusió d'aquests models arquitectònics, basats en el plantejament d'uns espais litúrgics altament funcionals i de rotunda senzillesa estructural.

La congregació de monges carmelites descalces, fundada per santa Teresa el 1562, va ser una de les que van adoptar aquests esquemes d'una manera més clara i decidida. Fou la pròpia fundadora qui, ja als primers establiments, va donar la pauta de la configuració d'uns cenobis definits per l'austeritat i la simplicitat dels paraments, adaptant-se a la regla primitiva, que propugnava un estil de vida basat en l'eremitisme i l'oració en solitari. L'aproximació a la figura de santa Teresa quant a fundadora ens permet descobrir la seva vessant més pràctica: la d’organitzadora, administradora, directora i, per sobre de tot, la d'instigadora d'una determinada manera d'entendre la vida religiosa i l'adaptació dels espais per a poder-la desenvolupar amb plenitud.

\section{1. «Grandísimo encerramiento, ansí de nunca salir como de no ver»}

Seguint els preceptes estipulats per sant Albert a la Regla primitiva, santa Teresa propugnava un estil de vida religiosa basada en l'eremitisme i l'oració en solitari. Les noves fundacions, doncs, havien d'establir-se a partir d'una clausura i un aillament estrictes respecte al món exterior mitjançant un alt mur que circumdés el monestir. Les cel les, seguint les disposicions de la Regla, havien de ser independents i despullades de qualsevol objecte que no fos estrictament necessari, per tal de facilitar l'obligació dels religiosos de romandre en solitari i dedicats a l'oració el màxim d'hores possible (Víctor de Jesús María: 123-203; Efrén de la Madre de Dios: 214; Smet: , vol. 2, 48). La Santa va fer servir en diverses ocasions la projecció del monestir com la materialització d’un paradís terrenal, que, alhora, esdevé una materialització gràfica de l'autèntic paradís celestial. Aquesta imatge d'aillament i reclusió, que tingué molt present quan gestà la seva primera fundació al convent de San José d’Àvila, es materialitzà amb els termes de «paraíso», «castillito» y «cielo» (Santa Teresa de Jesús 1996b: 3.2 i 13.7), i sorgeix també en alguns escrits de sant Joan de la Creu, que fa servir el topos de l'bortus conclusus — extret del Càntic dels Càntics_ - amb l'objectiu de configurar la idea de la vida monàstica com una mena de retorn al paradís, un jardí separat de la resta del món on el religiós se santifica i pot sentir-se més a prop de Déu (Howe: 95).

El concepte del jardí té una llarga tradició dins la cultura cristiana; és present ja als textos veterotestamentaris —al Gènesi com a Jardí de l'Edèn, i també al Càntic dels Càntics—, on es configura el ja anomenat model de l'hortus conclusus, molt popular en la tradició medieval. Aquesta és una figura present a la mística medieval; el monestir, com a àmbit propi del monjo, és el lloc 
on aquest desenvolupa la seva recerca de perfecció dins el món material i on aspira a retornar al paradís. I, com a tal paradís, pren la forma d'un jardí tancat, preservat del món exterior. Alguns estudiosos han vist, fins $\mathrm{i}$ tot, un important contingut doctrinal en la presència del jardí, com a alabança de l'amor a Déu, la caritas, en oposició a l'amor malentès a un mateix o a altres éssers humans, la cupiditas (Checa: 33; Chorpenning: 247). La relació amb la natura i la visió de la creació constitueixen en l'imaginari espiritual de santa Teresa una de les veus de Déu. Aquest concepte s’aproxima a una particular visió teològica del jardí, que està relacionada, de forma més o menys desenvolupada, a gran part dels ordes reformats i també dels nous ordes religiosos, en particular filipins, jesuïtes i camaldulenses (Sturm: 66).

L'existència d'hort permetia la instal lació de capelles o d'ermites on les religioses de les primeres fundacions descalces poguessin retirar-se per a resar en solitud, imitant l'estil de vida dels antics cenobis carmelitans. Aquesta tendència seria seguida poc després per les comunitats masculines, en les quals es pot detectar una certa inclinació cap a l'ascetisme pels llocs triats a l'hora de portar a terme els nous establiments. La importància que assolí aquest factor en la mentalitat de la fundadora explica la inclusió d'aquest precepte a les primeres constitucions de la congregació de carmelites descalços, redactades el 1581 (Regla primitiva 1581). De l'important paper que tingué el jardí en els primers cenobis carmelitans derivaria la tipologia del «deserts», cases de recés espiritual concebudes com a un apartament temporal del món, i per aquest motiu emplaçades a una considerable distància dels nuclis urbans. La pretensió d'aquest tipus d'establiments era conjugar la vida espiritual de comunitat (pròpia dels cenobites) amb la permanència en solitud en zones despoblades (pròpia dels anacoretes), constituint amb aquesta finalitat erms que sintetitzaven les pràctiques de tots dos.

El desig de santa Teresa, expressat en molts dels seus escrits, era que els convents fundats per ella s'apropessin a l'antiga Regla carmelitana en el sentit de ser baluards de l'afany de perfecció propi de la vida cristiana, refugis per llurs habitants, models de comportament per a la resta de cristians. Aquesta idea de perfecte aillament, però, topava frontalment amb la necessitat inqüestionable d'estar en contacte continu amb el món, del qual els religiosos s'havien d'abastir materialment a partir d' almoines. D'aquesta manera, tal com assenyalava Ruiz Soler, el tipus de vida propugnada pels ordes mendicants es convertia en una continua i irresoluble contradicció: per a arribar a una vida de perfecció calia apartar-se del món, però per a poder assolir aquest estat calia mantenir-se en contacte directe amb el món, en concret amb els fidels que a partir de llurs donacions feien possible la vida de clausura (Ruiz Soler: 65).

En la creació de monestirs hi havia dues opcions: o bé fundar en localitats pobres, apartades de nuclis de població importants, però amb una renda assegurada que permetés l'establiment, la construcció de l'edifici i la manutenció de la comunitat; o bé fundar en localitats riques, situades en rutes comercials importants, amb una considerable concentració de capital en mans de famílies recentment enriquides i disposades a prosperar socialment a partir del patronatge devocional. La primera fundació masculina de l'orde descalç a Pastrana, el convent de San Pedro, constitueix una 
excepció a aquesta norma, atès que aquesta era una població pobre, i l'establiment dels religiosos es produí sense que existís una renda assegurada. L'explicació radicava en la diferent naturalesa respecte a les fundacions femenines; els frares havien d'estar en contacte permanent amb els fidels per raó de les seves tasques educadores, evangelitzadores i — sobretot— sagramentals, i per tant no tenia gaire sentit plantejar fundacions amb renda amb la única finalitat de garantir la clausura completa dels religiosos, atès que aquesta seria sempre impossible d'acomplir en la seva totalitat (Ruiz Soler: 86).

Els emplaçaments més adients eren els que es trobaven allunyats dels seglars, però no fins al punt que aquest allunyament dificultés als religiosos l'assistència espiritual al poble —i per tant l'arribada d'almoines-. És a dir, els llocs més indicats eren els suburbis de les ciutats, on es donaven les dues condicions d'allunyament i proximitat alhora (Víctor de Jesús María: 163). Tanmateix, els establiments donaren prioritat als aspectes més pràctics de manera progressiva, intentant implantarse ben a prop dels centres urbans per tal d'assegurar-se una font d'ingressos infal lible, i deixant en un lloc secundari els aspectes espirituals. Teófanes Egido, estudiós de la figura de santa Teresa, posava en relleu el canvi sofert en l'esperit de l'orde a mesura que es produïen nous establiments; segons l'autor, analitzant el mapa de les fundacions portades a terme per la Santa, és apreciable en el cas de Castella una concentració en els nuclis més actius i més productius, és a dir, on s'evidenciava una més gran concentració de riquesa, i, per tant, una presència important de burgesia, indispensable com a protectora i finançadora de noves fundacions (Egido 1981: 188).

\section{2. «No consentir demasía en ser grandes las casas»}

El convent, doncs, fins i tot quan estava situat en un àmbit plenament urbà, era l'illa de solitud enmig de la mundanitat, i l'austeritat i el despullament amb què havien estat plantejats els seus paraments interiors i exteriors eren els millors exponents de la vida d'ascetisme viscuda darrere els seus murs. L'arquitectura era el vehicle a partir del qual els ordes religiosos mendicants manifestaven dins els nuclis urbans la seva opció de vida de santificació, però no a través de trets estilístics específics, sinó a partir del despullament. Santa Teresa va crear un nou tipus d'arquitectura basant-se en pressupòsits de pobresa, compartits no només per altres congregacions religioses similars, sinó, en general, per les tendències constructives del moment.

Quan parlem d'una arquitectura teresiana ho fem pensant en el conjunt de directrius marcades per santa Teresa, que després acabaran per perfilar el que coneixem com a «arquitectura carmelitana». La fundadora s'ocupà personalment de totes les fundacions portades a terme en vida seva: el lloc, l'edifici, les fonts d'ingressos, les religioses que havien d'habitar els convents. En el cas de la construcció del convent de descalces de San José de Malagón, a partir del 1568, va ser ella qui trià el terreny on s'havia d'emplaçar el monestir, va fer prevaldre el seu criteri per sobre del de l'arquitecte encarregat del projecte, i va decidir quins materials havien de ser utilitzats: calç, maó i bigues 
tosques de fusta (Florisoone: 482; Jiménez-Landi: 60). I en ocasió de la fundació del convent de Salamanca el 1570, la fundadora declarà ser entesa en qüestions d'obres, referint-se probablement a l'experiència que, després de les fundacions portades a terme, havia acumulat en el seu tracte amb mestres d'obres i amb problemes derivats de la construcció (García Hinarejos 1992: 250).

Santa Teresa afirmava que els edificis on s'havien d'instal lar els convents havien de ser «de manera que se pueda vivir, todo tosco y sin labrar, no mas de como no fuese dañoso a la salud, y ansí se ha de hacer siempre». Va manifestar en repetides ocasions que aquestes construccions havien de ser senzilles i petites, de sostres baixos, construïdes a partir del maó i la fusta —a excepció de les esglésies, on permetia més excessos, amb la incorporació de pedra i ferro-, acomplint estrictament les necessitats de la comunitat. La fundadora advertia de la fortalesa d'esperit i de la riquesa de vida interior que aquestes cases humils creaven en qui les habitava, al contrari de l'efecte que causaven els edificis excessivament sumptuosos:

\begin{abstract}
¡Oh, válame Dios, qué poco hacen estos edificios y regalos esteriores para lo interior! Por su amor os lo pido, hermanas y padres míos, que nunca dejéis de ir muy moderados en esto de casas grandes y suntuosas. (...) Verdaderamente he visto haber más espíritu y alegría interior cuando parece que no tienen los cuerpos cómo estar acomodados que después que ya tienen mucha casa y lo están (Santa Teresa de Jesús 1957: capítol XIV).
\end{abstract}

I en la Visita de las descalzas, l'any 1576, advertia que l'afany per condicionar els edificis podia portar a excessos:
No consentir demasía en ser grandes las casas, y que por labrar u añadir en ellas — si no fuere a gran necesidad - no se adeuden. Es mejor que se pase por trabajo de no muy buena casa, que no de andar desasosegadas y dar mala edificación con deudas u faltarles de comer (Santa Teresa de Jesús 1996a: capítol XII).

Aquest esperit de pobresa esdevindria, amb el pas del temps, més aviat un ideal, un estat espiritual a assolir, i no tant una evidència material de l'àmbit on s'havia de desenvolupar l'existència diària del religiós. El grau de complaença amb el qual santa Teresa portava a terme una fundació venia marcat per les possibilitats i els recursos econòmics que presentava, arribant algun cop a l'extrem de renunciar a establir comunitats que espiritualment haurien estat molt profitoses per la falta de bones comunicacions o la inexistència en aquests indrets de religiosos que asseguressin una dedicació a les ànimes dels fidels (Egido 1982: 25). Teresa estava disposada a renunciar a l'esperit de pobresa absoluta que havia marcat el naixement de l'orde descalç a canvi de poder disposar d'unes rendes que li permetessin la construcció i el manteniment dels seus convents. D’una altra manera, moltes de les seves fundacions haurien estat inviables. Entre la fidelitat total a la Regla primitiva i la possibilitat d'estendre les cases dels descalços i d'assegurar la seva subsistència, la Santa tria aquesta 
Carme Narváez. «Todo tosco y sin labrar»: el model conventual de santa Teresa i el seu reflex en la normativa arquitectònica de l'orde carmelità descalç

darrera opció.

\section{3. «Chicas, pobres, y hangostas»: mides, proporcions i uniformitat}

La ferma voluntat per part de l'orde descalç de fixar una normativa en la construcció dels seus convents es pot documentar ja en vida de la fundadora. Atorgada el juny del 1580 la llicència per a constituir capítol propi per part de Gregori XIII, pocs mesos més tard, el dia 5 de març del 1581, se celebrà al col legi de San Cirilo d'Alcalá de Henares el primer capítol general de l'orde carmelità descalç, durant la celebració del qual foren redactades les constitucions de la Província dels descalços (instituïda només dos dies abans), que serien publicades poc després a Salamanca. Entre els capítols d'aquesta primera reglamentació fixada per l'orde trobem la codificació de les normes a seguir en la fundació de nous convents, que evidencien el manteniment de la filosofia que santa Teresa havia imprès en els seus establiments: per una banda, la prohibició d'iniciar cap obra — fos de nova execució o de rehabilitació — sense comptar amb la prèvia llicència del prior provincial, que mostra la voluntat de mantenir una certa unitat de criteris constructius; i, per l'altra, l'obligació de mantenir en aquestes construccions l'esperit de pobresa propi de l'orde, evitant les comoditats excessives: «Mandamos que nuestras casas no se labren con edificios sumptuosos, sino humildes, y las celdas no sean mayores que de doce pies en quadro» (Regla primitiva, capítol II, 5).

Era el primer cop que la reglamentació carmelitana esmentava un patró dimensional, el dels dotze pams, aplicat en aquest cas a les cel les dels religiosos. Seguint la tradició de l'orde primitiu, la cel la del frare carmelità havia d'evocar la gruta d'Elies com a lloc on es desenvolupa la meditació i la recerca interior que porta a l'encontre amb Déu, i d'aquí el rigor i l'ascetisme que havien d'impregnar l'espai. Aquest mòdul serà desenvolupat tridimensionalment a les constitucions italianes de l'any 1605 (Constitutiones: 79), marcant una alçada proporcional de la cel la de dotze peus (patró de mesura tradicional al món italià) i, per tant, projectant un àmbit perfectament cúbic. El patró dels dotze peus —utilitzat ens els primers anys d'existència de les congregacions italianes - o dotze pams — a les congregacions de l'àmbit hispànic — esdevindria amb posterioritat una indicació normativa recurrent a la qual faran referència els futurs manuals constructius de la congregació, declinant-se en múltiples i submúltiples, és a dir, mòduls projectuals de referència per als ambients i els cossos de fàbrica: de sis, nou, dotze, divuit, vint-i-quatre, trenta-sis i seixanta-quatre pams (Sturm:73 i 182). El patró dels dotze peus/pams es presenta carregat de connotacions simbòliques procedents tal com remarca Sturm — de l'Antic Testament. Aquestes proporcions divines, que són al lusives a la Jerusalem celestial, serien adoptades com a model de perfecció i aplicades repetidament en el disseny arquitectònic i en la formulació de prototipus de ciutat ideal, i apareixeran sovint a la tractadística hispànica (Prado, Villalpando) com a símbol de perfecció. És més que probable, doncs, que aquest mòdul harmònic de dotze pams recollit a les primeres constitucions de la congregació carmelitana descalça sorgís amb la clara voluntat de revestir l'arquitectura de l'orde de connotacions místiques des dels seus inicis.

En aquestes primeres constitucions no es feia referència al temple quant a dimensions o a tipologia.

SCRIPTA, Revista internacional de literatura i cultura medieval i moderna, núm. 6 / desembre 2015 / pp. 176 - 189 ISSN: 2340-4841 · doi:10.7203/SCRIPTA.6.7829 
Fins a l'any 1587 no es van fixar unes mides per a marcar l'amplada màxima de les esglésies, que quedarà establerta en 8,40 metres a partir de la construcció de l'església del convent del Espíritu Santo de religiosos carmelites descalços de Toledo. Mentrestant, la principal atenció s'orientà, com acabem de veure en el cas de les cel les, cap a les dependències conventuals pròpiament dites. Ho podem constatar també en el cas de la infermeria; la seva presència quedà instituïda de manera oficial ja en aquesta primera reglamentació, on es va marcar la necessitat de la seva existència a tots els convents, incloent de manera conjunta la seva capella corresponent —adaptada a les dimensions de l'edifici sempre que aquestes ho fessin possible-, per tal que els religiosos malalts poguessin seguir els oficis a diari.

A les Constituciones redactades a Pastrana l'any 1602 els convents quedaren classificats en dues categories: grans i petits, $i$, en conseqüència ,van ser confeccionats dos models de traça per a ser aplicats en un o altre cas. En aquestes constitucions -impreses a Uclés el 1623- (Regla primitiva 1623) s'establiren també les mides màximes dels diversos àmbits que integraven els cenobis, plantejant una reducció respecte als mòduls aplicats en crides anteriors (Fontana Calvo: 228): esglésies d'entre vint-i-quatre i vint-i-set peus d'amplària, amb la corresponent proporció en llargària i alçada; cel les d'entre deu i dotze peus quadrats i una alçada de nou (a diferència de l'alçada marcada a les congregacions italianes); i cambres del pis baix d'onze o dotze peus d'alçada. Tanmateix, la consulta de les circulars i de les cartes pastorals generades al llarg del segle posterior, que continuen insistint en la necessitat d'atendre els límits marcats, permet afirmar que aquestes mides mai van ser aplicades amb rigor, i que, igual que altres pautes indicades per part de la congregació, van ser interpretades amb una gran laxitud.

Aquesta voluntat d'unificació en matèria de dimensions es mostrà més resolutiva en el si de la congregació italiana de carmelites descalços. Un any abans que el Papa decretés la província italiana com a congregació autònoma, l'any 1599 s'aprovava una primera versió de les constitucions que dedicava un capítol sencer al tema de la construcció dels convents. El títol d'aquest capítol, De nostrarum domorum aedificio ac pauperate, mostrava clarament la voluntat de controlar el procés de construcció, sotmès a la condició indispensable de la pobresa i la humilitat dels materials utilitzats i de les solucions aplicades (Sturm: 143). Amb posteriorirat, durant el capítol general celebrat a Roma l'abril del 1614, i sota el nom de Ordinatio circa fabricas, va ser aprovada una reglamentació que establia les mesures ideals dels convents de descalços a la península itàlica. Basades ara ja en la unitat de mida del pam utilitzada a les congregacions espanyoles —equivalent aproximadament a vint-i-cinc centímetres—, aquestes disposicions regulaven les proporcions màximes dels diversos espais dels cenobis, incloent àmbits que habitualment quedaven fora d'aquesta normativització, com el cor o la sagristia. La voluntat uniformitzadora de les autoritats italianes portava també a dictar normes en la configuració d'espais tan modestos com la cuina, els magatzems, les latrines o els galliners (De Mari: 361-363).

La congregació hispànica semblava estar més preocupada per l'aparença de senzillesa de les 
construccions que per l'aplicació d'unes mides estàndard, interpretant que la pobresa havia de fer-se visible més aviat a partir de la simplicitat i el despullament dels paraments, que eren els que ajudaven realment a mantenir una vida d'ascetisme. Les autoritats insistien especialment en la configuració de les cel les en ser els espais en què els religiosos passaven més hores al dia vivint en clausura i aillament de la resta del món. En aquest sentit, la Regla indicava que les cel『lles dels convents havien de ser independents $\mathrm{i}$ apartades les unes de les altres, «y que cada uno tenga la suia», mantenint en elles una total austeritat:

Las celdas de los frayles descalsos no han de ser curiosas, grandes, y anchorosas, como en otras Religiones santamente se permiten, sino chicas, pobres, y hangostas, y tales finalmente, que no se pueda llamar celdas, sino cellula, que es menos (Francisco del Santísimo Sacramento: 33r).

Era precisament l'esperit de pobresa la principal argumentació esgrimida en les reiterades crides a la uniformitat fetes per part de les autoritats de l'orde. I aquesta uniformitat havia de mostrar-se mitjançant un model de traça que fos aplicat en totes les noves fundacions.

La voluntat d'unificació quant a la projecció d'esperit de pobresa en les construccions es manifestà des dels primers anys, tot i no quedar especificada per l'orde en aquests termes concrets. La primera notícia en aquest sentit la coneixem a partir de la crònica de fra Joan de sant Josep, historiador de l'orde descalç a Catalunya en el segle XVIII, que assenyalava que entre les resolucions aprovades durant la celebració del primer capítol provincial dels descalços l'any 1590 al convent de Tàrrega, es trobava la relativa a la confecció de «una planta para las Fabricas de los conventos que se fueren fundando» (Juan de San José: 124). Aquesta voluntat va quedar més clarament manifestada a partir del 1594, quan fra Elías de san Martín accedí al generalat. Amb ell s’inicià el procés d'homogeneïtzació de l'arquitectura dels convents carmelitans, posat en marxa a partir de dues vies: en primer lloc, mitjançant un precepte adreçat als priors en el qual se'ls advertia severament que havien de seguir les directrius emanades del capítol, i, en segon lloc, enviant, a més, el tracista fra Francisco de Jesús a visurar els convents en construcció per tal d'assegurar el compliment d'aquesta normativa (Muñoz Jiménez 1990: 29).

El plantejament d'un model únic d'església arribaria amb el tombant de segle: l'any 1600 fra Francisco de la Madre de Dios, que substituïa fra Elías com a general, reuní a Madrid tots els membres de l'orde entesos en arquitectura amb la finalitat que establissin una traça única que passaria a partir d'aquell moment a ser obligatòria en la construcció de tots els nous temples carmelitans. Els resultats van ser divulgats mitjançant un document, denominat traz̧a moderada, que prenia com a model l'església del convent de San José de Malagón: nau única, absència de capelles laterals o fornícules a les parets, capçalera plana, transsepte incipient, pilastres en comptes de columnes, ordre toscà — triat, evidentment, per la seva extrema simplicitat—, coberta de volta 
de canó i, finalment, cúpula sobre el creuer. ${ }^{1}$ Va ser en la construcció de l'església del convent de San Hermenegildo a Madrid, l'any 1605, que aquesta traça fou aplicada per primer cop, esdevenint a partir d'aquest moment el prototipus per a la resta de convents de l'orde carmelità descalç.

La ferma voluntat que tots els nous convents prenguessin com a referència aquest model es manifestà al llarg dels anys amb diverses circulars i cartes pastorals. El març de 1626 el general fra Juan del Espíritu Santo insistia en una d'aquestes cartes sobre el fet que les traces no podien ser alterades en cap aspecte, i que tots els religiosos que tinguessin alguna responsabilitat en matèria artística durant el procés de construcció d'un nou convent les havien de seguir estrictament, a excepció dels casos en què existís una llicència del pare general o dels mateixos tracistes, tot i que es tractés simplement d'obrir una finestra o una porta. Per a fer realment efectiu aquest model normatiu calia, tanmateix, comptar amb artífexs de la construcció que n'estiguessin familiaritzats i que es fessin responsables de la seva aplicació. Els tracistes de l'orde descalç havien de ser els responsables del control exercit per les autoritats carmelitanes en matèria d'uniformitat.

En els primers anys de vida de l'orde, quan encara no s'havia establert la necessitat de l'existència de la figura oficial del tracista, era habitual que fossin els mateixos priors de les cases conventuals els qui confeccionessin les traces dels nous edificis, tant si la construcció es plantejava de nova planta com si es tractava de la reforma d'un edifici preexistent. Tenint en compte la inexperiència en el camp arquitectònic de la major part d'aquests priors, aquesta pràctica va comportar en molts casos l'existència de construccions molt deficients que amenaçaven ruïna poc temps després d'haver estat aixecades. La constatació d'aquests errors dins l'orde portà en algunes ocasions a malfiar-se de la intervenció en els projectes de mestres d'obres sorgits de la pròpia congregació, i per tant a la tendència a contractar tracistes o mestres d'obres seculars, malgrat que això signifiqués encarir notablement la construcció. Aquesta circumstància es donava, sobretot, en el cas que darrere el projecte es trobés un patrocinador que tingués mitjans econòmics i que es pogués permetre la contractació d'un professional de la construcció (Muñoz Jiménez 1990: 33).

Fra Ambrosio Mariano de san Benito (Ambrogio Mariano d'Azzaro), molt apreciat per santa Teresa, pot ser assenyalat com a un dels primers tracistes de l'orde de carmelitans descalços. En la seva qualitat de tracista $i$ enginyer hauria desenvolupat un paper important en els establiments inaugurals portats a terme per la fundadora, intervenint decisivament en la traça dels primers convents de l'orde descalç i, per tant, sent el responsable en gran mesura dels criteris generals de construcció dels nous monestirs (García Hinarejos 1993: 250). Tanmateix, a excepció d'algunes circulars o cartes pastorals que estableixen directrius puntuals, la documentació no permet concloure amb precisió quina mena de criteris eren aplicats en la formació o el reclutament d'aquests artífexs. Una

1 Un altre dels intents de fra Francisco de la Madre de Dios va ser traslladar als afores de les poblacions alguns convents establerts massa prop del centre dels nuclis urbans, o impedir l'establiment de fundacions noves. Tanmateix, aquesta voluntat durà el mateix que el seu generalat; un cop rellevat en el seu càrrec, la dinàmica d'assentaments cèntrics continuà (Silverio de santa Teresa: vol. 8., 163 i 702-704). 
de les escasses evidències documentals conegudes és una tardana carta pastoral, datada l'any 1698, en la qual el general de l'orde, fra Juan de la Anunciación, s'adreçava a tots els convents apuntant la conveniència que els frares llecs acceptats com a nous membres de les diferents comunitats tinguessin oficis útils a la religió, i entre aquests apuntava els d'encaixador, entallador, escultor, fuster, manobre, daurador o pintor, i, encara més, «que esten en dichas artes diestros y no sean principiantes» (San José: 122).

Les circulars que insisteixen al llarg dels anys sobre la mateixa necessitat de seguir les traces establertes per a la construcció de convents ens permeten evidenciar que els avisos dels generals sobre la matèria eren sistemàticament ignorats. Efectivament, al llarg de la segona meitat del segle XVII hom aprecia en l'arquitectura dels convents carmelitans una certa complexitat en els interiors, acompanyada d'una major riquesa en peces escultòriques i pictòriques, aspectes que denoten en general un esperit de relaxació en el si de l'orde. Una perfecta mostra n'és el contingut de la circular que redactà el pare general fra Diego de la Presentación el juny del 1657, en què, arran de la visita realitzada a diversos convents, mostrava la seva preocupació després d'haver constatat de quina manera es contravenien els decrets de rigor i austeritat marcats per les autoritats de la congregació. Durant aquestes visites el general havia vist temples que excedien del model pautat, tant en austeritat com en les seves mides; finestres obertes al carrer i al camp, fora de clausura, amb el consegüent destorb a la vida de meditació del frare descalç; utilització de rajoles a les parets de les esglésies i de lloses pel paviment; retaules amb talla excessiva; i, finalment, orfebreria i ornaments massa costosos (Arxiu de la Corona d'Aragó, Monacals-Hisenda, lligalls grans, 171, citat a Narváez 2003: 81-82).

\section{4. «Estilo ordinario y común de la Orden»}

L'expressió sorgí arran de la polèmica que generà dins de l'orde la construcció de la nova església del convent de San José d'Àvila (1608-1617), allunyada — segons els crítics- de l'austeritat i l'esperit de modèstia propis de la congregació (Muñoz Jiménez 1985). A partir d'aquest moment la fórmula esdevingué una crida habitual de referència en les directrius d'edificació i ornamentació del temples carmelitans. Tanmateix, difícilment els trets que defineixen les construccions teresianes poden ser identificats com a propis, atès que van ser manllevats d'una tendència constructiva identificable amb anterioritat a l'existència de l'orde; l'aplicació de la nau única, les capelles allotjades entre els contraforts, el cor elevat als peus del temple, la capçalera plana, el transsepte inclòs a les plantes, la utilització d'un ordre arquitectònic simple i despullat, són elements ja visibles a l'arquitectura conventual peninsular fins i tot abans de l'aplicació duta a terme en les nombroses fundacions que els jesuites endegaren a Castella, que foren assimilats per altres ordes religiosos preexistents o nascuts en aquesta època.

Muñoz Jiménez, autor d'un aprofundit i minuciós estudi sobre l'arquitectura en l'orde carmelità descalç, utilitzava l'expressió «legislación vigilante» per a fer referència a l'abundant recull de pautes, 
Carme Narváez. «Todo tosco y sin labrar»: el model conventual de santa Teresa i el seu reflex en la normativa arquitectònica de l'orde carmelità descalç

cànons i estàndards proporcionals que poden ser identificats en la quantiosa documentació generada per les autoritats de la congregació (1990: 44). L’orde de carmelites descalços, de manera similar al que succeí en altres congregacions religioses, generà una codificació en l'àmbit constructiu que pretenia la creació d'una estricta disciplina a la qual s'havien de sotmetre els tracistes i les noves construccions. El que buscaven les autoritats era bàsicament el control. I, tanmateix, aquest control escapà de les seves mans de manera reiterada, tal com hem posat en relleu en les pàgines precedents.

En aquest sentit, podem dir que la controvèrsia generada per la construcció de la nova església del convent de San José d'Àvila resulta paradigmàtica quant a l'existència entre els mateixos integrants de l'orde de dos sectors d'opinió que discrepaven respecte a com havien de ser plantejades les noves construccions; el primer defensava l'excepcionalitat de les proporcions i sumptuositat de l'edifici avilés tractant-se de la casa mare, i el segon considerava que era precisament el fet que es tractés de la casa mare el que requeria que el temple servís de model d'austeritat a futures edificacions. La voluntat pragmàtica de la fundadora pugnava amb la temptació de distingir-se en l'excepcionalitat. Finalment, l'obra va romandre amb la sumptuositat i la riquesa plantejades a la traça de Francisco de Mora. 
Carme Narváez. «Todo tosco y sin labrar»: el model conventual de santa Teresa i el seu reflex en la normativa arquitectònica de l'orde carmelità descalç

\section{Bibliografia}

Checa, Jorge (1986) Gracián y la imaginación arquitectónica: espacio y alegoría de la Edad Media al Barroco, Potomac, Scripta Humanistica.

Chorpenning, Joseph F. (1985) «The Monastery, Paradise, and the Castle: Literary Images and Spiritual Development in St. Teresa of Ávila», Bulletin of Hispanic Studies, 62, pp. 245-257.

Constitutiones carmelitarum discalceatorum congregationis S. Eliae anno 1605 latae (1968) [Strina, Joannes Marcus (ed.)]. Gènova, Tipo-Litografia Opera Ss. Vergine di Pompe.

De Mari, Niccolò (1996) «L'architettura dei Carmelitani Scalzi e i complessi genovesi di Santa Anna, Santa Maria della Sanità e San Carlo», dins Giordano, Saverio; Paolocci, Claudio (eds.), Nicolò Doria. Itinerari economici, culturali, religiosi nei secoli XVI-XVII tra Spagna, Genova e l'Europa, Roma, Institutum Historicum Teresianum, , pp. 357-388.

Efrén de la Madre de Dios (1963) «El ideal de Santa Teresa en la fundación de San José», Carmelus, 10, pp. 206-230.

Egido, Teófanes (1981) «El tratamiento historiográfico de Santa Teresa», Revista de Espiritualidad, 40, pp. 171-189.

—_. (1982) «Santa Teresa y su circunstancia histórica», Revista de Espiritualidad, 41, pp. 9-27.

Fernández Gracia, Ricardo; Echevarría Goñi, Pedro Luis (1981) «El convento e iglesia de los Carmelitas Descalzos de Pamplona. Arquitectura», Príncipe de Viana, 164, setembre-desembre, pp. 787-818.

Florisoone, Michel (1963) «Estética de Santa Teresa», Revista de Espiritualidad, 87-89, pp. 482-488.

Fontana Calvo, Celia (2011) «El desaparecido convento de San Alberto de Huesca y la arquitectura carmelitana», Argensola, 121, pp. 207-272.

Francisco del Santísimo Sacramento, Breve exposicion de nuestra Regla Primitiva, Arxiu General Històric de la Universitat de Barcelona, ms. 1113.

García Hinarejos, Dolores (1992) «Las ideas arquitectónicas de Santa Teresa de Jesús», dins I Congreso Internacional del Monacato Femenino en España, Portugal y América (1492-1992) II (Universidad de León, 1992), León, Universidad de León, Secretariado de Publicaciones, 2 vol., pp. 249-257.

- (1993) «La arquitectura de los carmelitas descalzos del siglo XVII en Valencia», dins Actas del Primer Congreso de Historia del Arte Valenciano (València, maig de 1992), Generalitat Valenciana, València, pp. 249-259.

Howe, Elizabeth Teresa (1988) Mystical Imagery. Santa Teresa de Jesús and San Juan de la Crur, Nova York, Peter Lang.

Jiménez Landi, Antonio (1970) «Santa Teresa de Jesús en su momento histórico», dins Puente, Joaquín de la (ed.), Santa Teresa y su tiempo, catàleg de l'exposició (Casón del Buen Retiro, Madrid 1970), Madrid, Comisaría General de Exposiciones, Ministerio de Educación y Ciencia, pp. 49-64. 
Carme Narváez. «Todo tosco y sin labrar»: el model conventual de santa Teresa i el seu reflex en la normativa arquitectònica de l'orde carmelità descalç

Juan de San José, Fray, Annales de los Carmelitas Descalcos de la Provincia de San Iosef en el Principado de Cathaluña, Arxiu General Històric de la Universitat de Barcelona, ms. 991

Martín González, Juan José (1976) «El convento de Santa Teresa de Ávila y la arquitectura carmelitana», Boletín del Seminario de Estudios de Arte y Arqueología, 42, pp. 305-319.

Muñoz Jiménez, José Miguel (1985) «El convento de «la Santa» en Ávila. Nueva documentación sobre la polémica del convento de Santa Teresa de Ávila (1652-1655): la arquitectura carmelitana en la disyuntiva manierismo v. Barroco», Monte Carmelo, 93, pp. 15-29.

—. (1990) La Arquitectura Carmelitana (1562-1800), Ávila, Diputación Provincial de Ávila- Institución Gran Duque de Alba.

Narváez, Carme (1995) «La gestació de l'estil arquitectònic carmelità; les primeres disposicions dels descalços respecte a la construcció dels seus convents», Locus Amoenus, 1, pp. 139-144.

- (2003) La arquitectura en la congregación de los carmelitas descalios (siglos XVI-XVIII), Burgos, Monte Carmelo.

—. (2005) «Els espais conventuals i la seva projecció eremítica: el desert de Cardó», Recerca, 9, pp. 237-254.

Regla primitiva y Constituciones de la Provincia de los frayles Descalzos de la Orden de $N^{a} S^{a}$ la Virgen del Monte Carmelo, 1581, Arxiu General Històric de la Universitat de Barcelona, ms. 412.

Regla primitiva y Constituciones de los Religiosos Descalzos de la Orden de Nuestra Señora del Carmen del Monte Carmelo de la Congregación de España, Uclés, 1623.

Ruiz Soler, Luis (1970) La personalidad económico administrativa de la Santa Madre Teresa de Jesús, Zarauz, Icharopena.

San José, Félix Mateo de (1948) «Canon arquitectónico en la legislación carmelitana», Monte Carmelo, 52, pp. 117-122.

Silverio de Santa Teresa (1935-1952) Historia del Carmen Descalzo en España, Portugaly América, Burgos, Monte Carmelo, 15 vol.

Smet, Joaquín (1990) Los Carmelitas. Historia de la Orden del Carmen, II, Madrid, Biblioteca de Autores Cristianos, 3 vol.

Sturm, Saverio (2002) L'architettura dei Carmelitani Scalz̨i in età barocca. Principii, norme e tipologie in Europa e nel Nuovo Mondo, Roma, Gangemi Editore.

Teresa de Jesús, Santa (1957 [1ª ed. 1610]) Libro de las fundaciones, Madrid, Espasa Calpe.

—_. (1996a [1a ed. 1576]) «Modo de visitar conventos», dins Teresa de Jesús. Obras completas [Órdoñez Villarroel, Manuel (ed.)], Burgos, Monte Carmelo.

—. (1996b [1 ${ }^{\mathrm{a}}$ ed. 1583]) Camino de perfección, Madrid, Espasa Calpe.

Verdú Berganza, Leticia (1996) La «arquitectura carmelitana» y sus principales ejemplos en Madrid (siglo XVII),

SCRIPTA, Revista internacional de literatura i cultura medieval i moderna, núm. 6 / desembre 2015 / pp. 176 - 189 ISSN: 2340-4841 $\cdot$ doi:10.7203/SCRIPTA.6.7829 
Carme Narváez. «Todo tosco y sin labrar»: el model conventual de santa Teresa i el seu reflex en la normativa arquitectònica de l'orde carmelità descalç

tesi doctoral, Departamento de Historia del Arte II (Moderno), Facultad de Geografía e Historia, Universidad Complutense de Madrid.

Víctor de Jesús María (1948) «La exposición canónico-moral de la Regla carmelitana según los comentadores descalzos», Ephemerides Carmeliticae, 2, pp. 123-203. 